\title{
Estimating river discharge during ice breakup from near- simultaneous satellite imagery
}

\author{
Spyros Beltaos \\ National Water Research Institute, Environment Canada \\ 867 Lakeshore Road, Burlington, ON, L7R 4A6 \\ Spyros.Beltaos@ec.gc.ca
}

\author{
Andreas Kääb \\ Department of Geosciences, University of Oslo \\ PO Box 1047, 0316 Oslo, Norway \\ kaeaeb@geo.uio.no
}

\begin{abstract}
River ice breakup has many socio-economic and ecological implications that primarily result from the formation and release of major ice jams. A key driver of breakup processes is the river discharge, but the presence of fractured ice sheets or moving ice rubble render its measurement or estimation very difficult. Here, we exploit the fact that the acquisitions of individual images of a satellite stereo scene are separated by about one minute. Between three stereo images taken from the PRISM instrument onboard the Japanese ALOS satellite on May 20, 2010, we track the displacements of river ice debris using automatic image correlation along a $40 \mathrm{~km}$ long reach of the Mackenzie River, just above the entrance to its delta. This results in an almost complete ice velocity field over the river area studied with a spatial resolution of $25 \mathrm{~m}$ and an accuracy of $\sim 0.07 \mathrm{~m} / \mathrm{s}$ for the speeds. Channel bathymetry, slope, and hydraulic resistance along the study reach, known from previous studies, are then utilized to compute discharge at 15 cross sections. Calculated values vary from $\sim 20000$ to $\sim 27000 \mathrm{~m}^{3} / \mathrm{s}$ and are comparable to 23800, the value estimated by Water Survey of Canada. Variability is much smaller, and close to that of conventional flow measurements, within the relatively straight sub-reach immediately upstream of the delta, where the effects of boundary constraints caused by a sharp bend farther upstream are minimal. This study proves for the first time that it is feasible to estimate river discharge during ice breakup at a reasonable accuracy using near-simultaneous satellite images. While this work had to rely on data that were coincidentally contained in satellite archives, special satellite or aircraft acquisitions could greatly enhance the probability of obtaining suitable data and thus the applicability of the method.
\end{abstract}

Keywords: Ice run, logarithmic profile, river discharge, satellite, stereo imagery, velocity field 


\section{Introduction}

The breakup of ice on rivers has numerous socio-economic and ecological impacts (Burrell, 2008; Prowse and Culp, 2008). Flooding and damage to property and infrastructure are two well known, and often fearsome, results of ice jamming that accompanies dynamic breakup events. Less well known, but just as important are such impacts as ecosystem disturbance, disruption of the biota community, abrasion of stream banks, alteration of channel morphology, transport of large quantities of fine-grained material and associated contaminants, and degradation of water quality (Beltaos, 2007). Breakup ice jamming can also be beneficial, however. For example, it has been shown to be a controlling factor for the hydroecology of the Mackenzie River Delta (Marsh et al., 1993), where ice jams can raise water levels to much higher elevations than open-water floods. The resulting flooding and replenishment of delta lakes with river water, sediment, and nutrients, plays a key role in the maintenance of their aquatic ecosystems. The issue of climate change has added urgency to the need for improved understanding of river ice processes with a view toward improved predictive capability as a means of quantifying climate-related long-term changes to river ice regimes.

One of the key drivers of river ice breakup is the flow discharge. Its magnitude and rate of rise, as a result of spring snowmelt and/or rain-on-snow precipitation during mid-winter thaws, largely determine the severity and persistence of ensuing ice jams, and the associated water levels (Beltaos, 2008a, 2008b). For the Mackenzie, and possibly other major northern rivers, breakup discharge is also an important variable controlling the fluxes of freshwater, sediment, and nutrients to the Arctic Ocean (Emmerton et al., 2008).

River flow is typically determined by means of hydrometric gauging stations, where rating curves and tables have been developed, relating flow to river stage. Such relationships are reasonably reliable under open-water conditions, but do not apply when ice is present. Though some allowances can be made for the effects of intact sheet-ice covers (Beltaos, 2011), flow estimation becomes highly uncertain during the breakup period, involving errors as high as 50\% (Rosenberg and Pentland, 1983; Melcher and Walker, 1992; Shiklomanov et al., 2006). Such errors arise from the presence of stationary and moving ice rubble, ice jams, and sharp waves generated by ice jam releases, known as javes (White and Beltaos, 2008; Jasek and Beltaos, 2008; Beltaos, 2013).

As conventional measurement of discharge is not possible during breakup, consideration has been given to estimating via measurement of the surface velocity field, as revealed by the motion of ice blocks (Jasek et al., 2001). The basic idea is to deduce vertically-averaged velocities via established hydraulic principles, and then integrate incremental discharges across the channel using independently measured local bathymetry and water levels. Typically, such techniques involve oblique photographs and video recordings (Jasek et al., 2001; Muste et al., 2008; Kim et al., 2008; Jodeau et al., 2008). Satellite imagery has been utilized more recently (Kääb and Prowse, 2011) to determine the velocity of ice floes carried along by the flow during the breakup of river ice.

Data from airborne or spaceborne platforms have, to our best knowledge, so far only been little developed and used to observe water flow and related processes (Kääb and Prowse, 2011). Previous relevant studies investigated, for example: subtle river-ice deformation using radar interferometry (Smith, 2002; Vincent et al., 2004); ocean currents from repeat spaceborne optical, thermal or microwave imagery, such as by tracking sea-ice or seasurface temperature features (Lavergne et al., 2010; Matthews, 2009); river-ice properties and 
density from radar imagery (Mermoz et al., 2009; Unterschultz et al., 2009); flow velocities from suspended-sediment concentrations in optical satellite images (Pavelsky and Smith, 2009). River and ocean currents have in particular been derived using spaceborne and airborne alongtrack radar interferometry (Goldstein and Zebker, 1987, Graber et al., 1996, Siegmund et al., 2004, Romeiser et al., 2007, Romeiser et al., 2010). The time interval or the related angular difference between alongtrack stereo imagery, originally designed to map terrain topography, have so far been little exploited for water applications, but have been used to derive vehicle and wave speeds and ocean currents (Garay, 2007, Matthews, 2005, Matthews and Awaij, 2010; de Michele et al., 2012). Kääb and Prowse (2011) tracked river ice debris over a time interval of approximately 1 minute between the partners of satellite stereo imagery to estimate for the first time twodimensional surface water velocity fields over entire river reaches. It is this latter technique we exploit further in the current study. Building on the work of Kääb and Prowse (2011), flow discharge has in this study been estimated from satellite imagery during the ice breakup of May 2010 in the Mackenzie River, within a $40 \mathrm{~km}$ reach immediately upstream of the Mackenzie Delta (Fig. 1).

The objectives of this paper are to (a) exploit further the methodology of processing successive, but nearly simultaneous, satellite images for quantifying the surface velocity field of a river; and (b) assess the hydraulic principles and ancillary survey data that are needed to estimate discharge once the velocity field is known. Following background information on the hydraulic relationships involved in discharge calculation via surface velocity distributions, the study area and ice breakup conditions associated with the time when the images were obtained are described. Next, the methods used in the processing of the images and the resulting data on the velocity field are presented. Various assumptions and procedures involved in the discharge computations are then outlined and the final results on discharges at 15 crosssections of the river presented. Finally, limitations and possible improvements to the present approach are discussed.

\section{Converting surface velocity data to flow discharge}

For fully rough turbulent flow, as is almost always the case in natural streams, the well known logarithmic velocity distribution in the vertical direction reads (e.g. Yalin, 1977)

$u=\frac{u_{*}}{\kappa} \ln \left(\frac{y}{k_{s}}\right)+8.5$

where $\mathrm{u}=$ longitudinal velocity; $\mathrm{y}=$ vertical distance above the channel bed; $u_{*}=$ shear velocity, defined as the square-root of the bed shear stress divided by the density of water; $\mathrm{k}_{\mathrm{s}}=$ equivalent sand-roughness height of the channel bed; and $\kappa$ is the Von Karman constant, typically equal to 0.40 . Integration over y gives the mean velocity $\left(\mathrm{u}_{\mathrm{m}}\right)$ as

$u_{m}=\frac{u_{*}}{\kappa} \ln \left(11.0 \frac{h}{k_{s}}\right)$

in which $\mathrm{h}=$ flow depth

From Eq. 1, the velocity at the water surface (y $=\mathrm{h}$ ) can be written as

$u_{\text {surf }}=\frac{u_{*}}{\kappa} \ln \left(30.1 \frac{h}{k_{s}}\right)$

From Eqs. 2 and 3, it can be shown further that the mean-to-surface velocity ratio is given by:

$\frac{u_{m}}{u_{\text {surf }}}=\frac{1}{1+\sqrt{f / 1.28}}$

where $\mathrm{f}$ is the Darcy-Weisbach friction factor [defined as $8\left(\mathrm{u} * / \mathrm{u}_{\mathrm{m}}\right)^{2}$ ]. The friction factor is 
related to the more commonly used Manning hydraulic resistance coefficient, $\mathrm{n}$, according to the equation:

$$
n=0.113 h^{1 / 6} \sqrt{f} \quad \text { (metric units) }
$$

Therefore, Eq. 4 can also be written in terms of n:

$$
r_{V} \equiv \frac{u_{m}}{u_{\text {surf }}}=\frac{1}{1+7.82 h^{-1 / 6} n}
$$

For any one natural stream, the value of $n$ is constant over a sizeable range of flow. Moreover, the small exponent of the depth in Eq. 6 indicates limited variability of the velocity ratio. For the current application in the lower Mackenzie River, the Manning coefficient has a value of 0.025 (Beltaos, 2012). With a typical depth range of 10 to $30 \mathrm{~m}$, known from previously surveyed bathymetry, Eq. 6 indicates that the velocity ratio, $\mathrm{r}_{\mathrm{V}}$, varies within a very narrow range, i.e. from 0.88 to 0.90 . Consequently, this parameter has been fixed at 0.89 for all subsequent computations.

Jasek et al. (2001) used a value of 0.88 for an application in the Yukon River, based on an assumed one-seventh power law for the velocity distribution. [Power laws are sometimes used in hydraulics as convenient alternatives to the logarithmic law. The value of the exponent is related to the degree of turbulence in the flow, and thence to the hydraulic resistance; a value of $1 / 7$ is very common]. Kim et al. (2008) used a value of 0.85 and quoted the range $0.79-0.92$, which was deduced from laboratory experiments by Polatel (2005) simulating shallow flows over rough beds. Jodeau et al. (2008) deduced an average value of 0.79 for a mountain stream application, based on measured velocity profiles. All of these values are consistent with the structure of Eq. 6, which suggests that shallow flows over rough streambeds have lower values of $r_{v}$ than deep rivers of moderate boundary roughness.
Ordinarily, the unit discharge $\mathrm{q}$ [discharge per unit channel width] at any given vertical is equal to the product of depth and mean velocity $\left(\mathrm{hu}_{\mathrm{m}}\right)$. However, in the case of a dense ice run, the unit discharge comprises water flowing under the ice and water moving along with, and inside the porous ice layer:

$q=r_{V} u_{i c e} h+p u_{i c e} t_{s}$

where the ice velocity, $u_{i c e}$, is now the surface velocity and $h$ is the net flow depth underneath the ice layer. The quantities $t_{s}$ and $p$ respectively represent the submerged portion of the thickness and the porosity of the ice layer. None of these variables are known in the present application, but the small magnitude of the second term on the right-hand-side of Eq. 7 relative to the first term suggests that even mere estimates would have little impact on the value of q.

The porosity of the moving ice layer can be calculated from

$p=1-C_{s}\left(1-p_{R}\right)$

where $\mathrm{C}_{\mathrm{s}}=$ surface concentration of running ice (estimated visually from the satellite images); and $\mathrm{p}_{\mathrm{R}}=$ porosity within the moving rubble. For breakup ice jams, $p_{R}$ is taken as 0.4 but its value should be higher for running rubble, owing to dispersion effects. This quantity has also been estimated visually. Both $\mathrm{C}_{\mathrm{s}}$ and $\mathrm{p}_{\mathrm{R}}$ change along the reach, depending on how dense and confined the ice run appears to be at different locations. As an example, a surface concentration of $80 \%$ combined with a rubble porosity of 0.5 results in an over-all porosity, $\mathrm{p}$, of 0.6 .

If the lateral distribution of surface velocity at a given cross section (XS for short) and the local river bathymetry are known, Eq. 7 can be used to determine $\mathrm{q}$ as a function of the transverse distance $\mathrm{z}$, and then to integrate across the channel to find the total flow discharge. 
However, it should be kept in mind that Eq. 7 is based on the assumption that the surface ice layer does not impede the water motion so that the velocity distribution under it is of the logarithmic kind, as expressed in Eq. 1 and illustrated in Fig. 2a. This assumption may not apply where the ice run is dense and constrained by channel morphology (e.g. sharp bends) and strong ice-bank interactions. In such instances, the velocity profile would likely exhibit a maximum at some distance below the bottom of the ice layer (Fig. 2b), resulting in a higher value of the ratio $r_{V}$ than for unconstrained flow. Consequently, Eq. 7 would tend to underestimate the discharge when $r_{v}$ is fixed at the unconstrained-flow value.

\section{Study area and ice breakup conditions}

The study area comprises a $40 \mathrm{~km}$ long reach of the Mackenzie River, starting at the entrance to the Mackenzie Delta at Point Separation and extending for some 40 river kilometers upstream (Fig. 1). During previous studies on ice breakup and jamming processes in the Mackenzie Delta (Beltaos et al., 2012), a total of 15 XSs have been surveyed along this reach. The surveyed bathymetry is illustrated in Figs 3 and 4, respectively depicting a typical $\mathrm{XS}$ and the longitudinal variability of the channel thalweg. The latter is the locus of minimum riverbed elevations, which generally vary between -10 and $-15 \mathrm{~m}$. The very deep section near $\mathrm{km} 24$ (Fig. 4) corresponds to the tight bend where the mouth of Arctic Red River is located (Fig. 1). The water level data in Fig. 4 underscore the flatness of the Lower Mackenzie River; a linear trend line fitted through the data points (not shown) indicated a slope of only $0.027 \mathrm{~m} / \mathrm{km}$. This figure can be contrasted with the range 0.1 to $1 \mathrm{~m} / \mathrm{km}$, which describes the vast majority of sizeable rivers.

A hydrometric gauge, operated by Water Survey of Canada (WSC), is located on the right bank across from the mouth of Arctic Red River. The station identification number is 10LC014 and the gauge name, "Mackenzie River at Arctic Red River", is herein abbreviated to MARR. As noted by Beltaos $(2011,2012)$, the slope of the water surface in the lower Mackenzie River changes with discharge and also depends on whether there is ice on the river. This variation results from the partial control exerted by the base level of Beaufort Sea. Using the gauge rating table, along with the surveyed bathymetry and a bed Manning coefficient of 0.025 , it is possible to deduce the variation of the water surface slope with discharge under open-water conditions. For the common range of open-water discharges, 10000 to $20000 \mathrm{~m}^{3} / \mathrm{s}$, the slope increases from 0.016 to $0.036 \mathrm{~m} / \mathrm{km}$.

Breakup in the study area typically occurs during the second half of May and is triggered by the arrival of the spring flood, which is driven by snowmelt in upper parts of the basin. Major ice jams upstream of Point Separation may produce sharp waves (or "javes") and huge ice runs when they release. These ice runs are often arrested in Middle Channel, the largest of the many Delta channels, where ice jams are known to form as far north as Horseshoe Bend ( $\sim 80 \mathrm{~km}$ below Point Separation) and even some kilometres beyond. Such jams raise water levels and divert water westwards, enhancing flood risk near the community of Aklavik. Ice jams are also known to form in the upper reaches of East Channel as it branches off the Middle Channel below Point Separation. Moreover, the high water levels caused by Delta jams result in essential replenishment of many lakes, especially those of higher elevation, with water, sediment and nutrients. Backwater from ice jams in the delta influences the water level at MARR and is often responsible for the local peak stage for the year. The discharge is a key factor in breakup and ice jamming processes, but its magnitude is difficult to assess, owing to the highly dynamic ice effects on stage and unsafe access conditions for measurements. As will be shown in the following sections, satellite imagery can be a useful tool in estimating discharge during breakup. 
The May 20, 2010 satellite images of this study clearly indicate the presence of an ice run within the entire study reach. At the time when the images were taken (1344 h, MST) the MARR gauge record indicates that the water level was at $10.20 \mathrm{~m}$ (Geodetic elevation) and was decreasing throughout the day. This implies that the jave associated with the ice run was in its falling limb while the discharge should increase somewhat in the downstream direction. The rate of change of water level provides an indication of the spatial gradient of discharge via the equation of continuity:

$$
\frac{\partial y}{\partial t}+\frac{\partial q}{\partial x}=0
$$

in which $\mathrm{y}=$ water surface elevation; $\mathrm{q}=$ discharge per unit channel width; $\mathrm{t}=$ time; and $\mathrm{x}$ $=$ longitudinal distance. The rate of decrease in water level (Fig. 5) during the estimated 6 hours of flow travel time from one end of the study reach to the other is $\sim 0.5 \mathrm{~m} /$ day or $\partial \mathrm{y} / \partial \mathrm{t} \sim 5.8 \times$ $10^{-6} \mathrm{~m} / \mathrm{s}$. With typical channel width of $\sim 1000$ $\mathrm{m}$, Eq. 9 gives $\partial \mathrm{Q} / \partial \mathrm{x} \sim 5.8 \mathrm{~m}^{3 /} \mathrm{s}$ per $\mathrm{km}(\mathrm{Q}=$ discharge), which translates to a difference of $230 \mathrm{~m}^{3} / \mathrm{s}$ over the $40 \mathrm{~km}$ study reach. This is a negligible quantity relative to the magnitude of the prevailing discharge.

According to the WSC "HiWater" reports, which are issued daily during the spring freshet and ice breakup period for the main rivers of the Mackenzie Basin, a relatively short ice jam had formed in the upper Delta. This jam would have likely caused some backwater at MARR, while being lengthened by the incoming ice run. The mean daily flow at MARR for May 20, 2010 has been estimated as $23800 \mathrm{~m}^{3} / \mathrm{s}$ by WSC. According to the gauge rating table, the corresponding open-water stage is $6.9 \mathrm{~m}$, indicating a jam-related effect of $3.3 \mathrm{~m}$. Of course, the value $23800 \mathrm{~m}^{3 /} \mathrm{s}$ is a mere estimate, but its magnitude leaves no doubt as to the presence of backwater.
To determine flow areas at the various XSs in the study reach, it is necessary to know the applicable water levels. This information can be generated from the known water level at the MARR gauge in conjunction with an estimate of the prevailing water surface slope. Measurements in 2008 (Beltaos and Carter, 2009; Beltaos et al., 2012) indicated a slope of $0.017 \mathrm{~m} / \mathrm{km}$ between MARR and Point Separation during an ice run that was feeding an ice jam in Middle channel. This value was used as a first approximation in the flow computations (to be described in the next section) and refined by checking against the implied value of the bed Manning coefficient, $\mathrm{n}_{\mathrm{b}}$. This resulted in a final choice of 0.028 $\mathrm{m} / \mathrm{km}$, which is considered reasonable because the much more extensive jam of 2008 would have caused more pronounced backwater at MARR and thence a lower water surface slope. From the viewpoint of accuracy, exact knowledge of the slope is not crucial in this flat reach. For instance, a slope error of $0.01 \mathrm{~m} / \mathrm{km}$ (representing $\sim 30 \%$ in the present context), will generate an error of at most $20 \mathrm{~km} \times 0.01 \mathrm{~m} / \mathrm{km}$ $=0.2 \mathrm{~m}$. With a typical channel width of 1000 $\mathrm{m}$, the latter value translates to an error of 200 $\mathrm{m}^{2}$ in cross-sectional area, or $\sim 1 \%$ of the typical area value of $16000 \mathrm{~m}^{2}$.

\section{Satellite measurements}

\subsection{Data and methods}

To assess ice conditions and measure ice velocities in this study we used a triplet stereo scene from the Panchromatic Remote-sensing Instrument for Stereo Mapping (PRISM) on board the Japanese ALOS satellite. The instrument carries three telescopes: one pointing forward ( $\mathrm{F}$ in Fig. 6) in flying direction with about $24^{\circ}$ from nadir, one pointing nadir $(\mathrm{N})$, and one pointing backward in flying direction (B). Images from all three telescopes are combined so that each triplet data set contains the forward, nadir and backward views on the 
same scene. By necessity the triplet images of a scene stem from slightly different times with $45 \mathrm{~s}$ time separation between the forward and nadir as well as the nadir and backward looking data, and thus 90 s between the forward and backward data, respectively. The data set used in this study was taken on May 20, 2010, 20:44 UTC (13:44 MST) with $2.5 \mathrm{~m}$ nominal ground resolution. No other optical stereo data under breakup or freezeup conditions suitable for tracking ice debris are available for the river reach studied. Rivers during ice breakup or freezeup have so far rarely been the explicit targets of satellite stereo acquisitions so that data that allow for river ice tracking can be found in the archives only occasionally (Kääb et al., 2013).

During acquisition time of our MARR data set, most of the river surface was covered by ice debris visible in the images except at some marginal sections, as shown in Fig. 7. Enlarged versions of various sub-reaches (Fig. 8) show considerable detail and provide a "feel" for the texture of the river surface during the ice run (see also Supplementary data). Large ice slabs within the rubble are clearly distinguishable by their white colour in Fig. 8 and their movement (or non-movement) can be visualized by comparing their respective locations relative to the channel banks in the two images (see also Supplementary data). Also evident is the shear line that develops between moving and shorefast rubble, a familiar feature of ice breakup in rivers.

From simple visual inspection of the images and flickering between the stereo partners (see Supplementary data) it becomes already clear that at several sections of the river reach ice floes are interfering with each other. Consequently, lateral friction, and even blocking, may be expected to develop between such floes, thus suggesting that the river ice does not accurately represent water flow everywhere on the entire river surface observed.
The PRISM stereo images were projected to UTM zone 8 and re-sampled to $2 \mathrm{~m}$ resolution using bilinear interpolation and based on the satellite position and viewing direction provided with the data. The

initial geo-reference was then corrected by a north-west shift of about $20 \mathrm{~m}$ using a ground control point close to the river, which is visible in the satellite data and was surveyed in situ by a code-based GPS receiver. We estimate the final absolute geo-reference accuracy of our data and results to be approximately $\pm 5 \mathrm{~m}$ or better. The forward and backward data were co-registered to the nadir data, which is the viewing direction with least topographic distortions, using a firstorder polynomial transformation based on stable objects at surface water level along the river margins, and resulting in a relative accuracy between the final image products at sub-pixel level. The satellite data used refer to the WGS84 ellipsoid, which is used for UTM projections, so that the image scale also refers to ellipsoid level. Any difference between the ellipsoid level and the real elevation of the terrain studied would thus result in a small scale error in the images and results derived from them, because the observed scene is in such a case actually closer to the satellite instrument than assumed, i.e. than the ellipsoid. This terrain elevation above ellipsoid is composed of the elevation of the terrain above sea level (the so-called geoid; asl.) and the height difference between ellipsoid and geoid (the so-called geoid undulation). The water level at the river segment studied here is about $10 \mathrm{~m}$ asl. and the geoid undulation about $1 \mathrm{~m}$, making the overall scale difference between the river surface elevation and the UTM reference ellipsoid with respect to the $\sim 700 \mathrm{~km}$ satellite orbit negligible. Moreover, the low slope on the order of $\sim 0.03 \mathrm{~m} / \mathrm{km}$ that has been estimated for the river reach (see also section 3 ) at the time the images were taken rendered 
negligible the correction of topographic distortions on the water surface.

Ice debris was then tracked between all three image-pair combinations possible (forwardnadir, nadir-backward, forward-backward) with sub-pixel precision by maximizing the double normalized cross-correlation coefficient on small image templates using the free software Correlation Image AnalysiS (CIAS ;Kääb and Vollmer, 2000; Heid and Kääb, 2012; Kääb, 2013). We used two distributions of measurement points: first, a regular grid over the entire river reach covered by the satellite data (Figs. 7 and 9), and, second, regularly spaced points along the 15 cross-sections. For the entire river surface contained in the scene, surface velocities were measured with $25 \times 25$ pixel sized templates (equivalent to $50 \mathrm{~m} \times 50 \mathrm{~m}$ ) over a $50 \mathrm{~m}$ grid resulting in $\sim 25,000$ measurements. Erroneous measurements were filtered out by a threshold on the correlation coefficient and a $3 \times 3$ moving window median filter. A few remaining obvious outliers, such as singular vectors pointing upstream, were removed manually. The results from the three image combinations (F-N, N-B, F-B) were very similar for the purpose of studying the velocity field of the entire reach and thus only the results from one pair are shown in Fig. 9

Also shown in Fig. 9 are the locations of the 15 XSs for which the channel bathymetry has been surveyed on different occasions and for which detailed ice velocities have been measured. Section numbers 1 to 5 pertain to a 2005 survey, intended to characterize the bathymetry within a short reach centered at the MARR gauge. Section numbers 17 to 26 refer to a 2009 survey that was carried out to furnish supplementary data for analysis and interpretation of ice breakup observations and measurements from the May 2008 event.

For the XSs, coordinates of points with $25 \mathrm{~m}$ regular spacing along the profile axes were produced and image matching performed at these locations, also using $25 \times 25$ pixel sized templates $(50 \mathrm{~m} \times 50 \mathrm{~m})$. These raw results were pre-filtered similar to the entire velocity field, using a threshold on the correlation coefficient, and a few remaining obviously spurious vectors removed manually. The remaining vectors (Easting and Northing displacements in UTM system) were then transformed to the crosssection profiles to obtain three data components: (i) the distance of measurement location from the left profile origin (as seen in river flow direction), (ii) the velocity component normal to the profile, and (iii) the component parallel to the profile. In a next step, the results of the $45 \mathrm{~s}$ forward-nadir and $45 \mathrm{~s}$ nadir-backward measurements were compared and displacements that were smaller than two times the standard deviation between both measurements (i.e. 2-sigma level) were marked as being not significantly different from zero and later set equal to zero in discharge computations. Displacements of the $90 \mathrm{~s}$ forward-backward interval turned out to be more prone to gross errors due to stronger changes of the ice debris pattern matched over the longer time lag. The 90s interval was therefore not used for discharge estimates.

For both the complete grid and the crosssections the resulting displacements are converted to velocity using the time interval between the stereo images. Accuracy of the final velocities is estimated in two ways: first, based on reference measurements to stationary shore ice resulting in a standard deviation of $\sim \pm 0.7$ pixels $( \pm 1.3 \mathrm{~m}, \pm 0.03 \mathrm{~m} / \mathrm{s})$. Second, the differences between the forward-nadir and nadir-backward measurements give a mean deviation of $\sim 0.2$ pixels, i.e. no systematic offset between all three images, and a standard deviation and RMS of $\sim \pm 1.5$ pixels $( \pm 3 \mathrm{~m}$, $\pm 0.07 \mathrm{~m} / \mathrm{s}$ ). The latter accuracies are lower than the first ones because they include the definition uncertainty of floating ice debris features over $45 \mathrm{~s}$ and any changes of ice velocity over the $90 \mathrm{~s}$ of total acquisition time, and are thus more representative of our velocity measurements. 


\subsection{Velocities}

Ice speeds of up to $2 \mathrm{~m} / \mathrm{s}$ are evident in Fig. 9 while there appears to be significant variability in both the longitudinal and transverse directions. Transverse variability is common in ice-free rivers and it is therefore difficult to discern any ice effects on the transverse velocity distributions in Fig. 9. More interesting in this context is the longitudinal variability, which suggests that ice slows down at bends and picks up speed as it exits them. As there are no comparable open-water data, it is not possible to establish with certainty that this type of variability is, at least in part, caused by the presence of the ice. Nevertheless, the high concentration of the ice run does suggest that ice motion at bends is far more constrained than motion in straight reaches, which is consistent with the speed distribution shown in Fig. 9 (see also Supplementary data). In turn, this implies that the under-ice velocity distribution at bends is more likely to be of the type shown in Fig. $2 b$ than in Fig. 2a, at least over a part of the channel width.

Figure 10 shows simultaneous enlarged views of the raw image and of the surface speed distribution at Sections 17, 23, and 22, as examples of relatively unconstrained, moderately constrained, and highly constrained ice movement conditions (see also Supplementary data). Velocity vectors are superimposed on the raw images of the three sections. Section 17 (Fig. 10 top) is located in a fairly wide, straight reach, not far from the Delta entrance at Point Separation. Here, there are sizeable open-water areas on both sides of the ice run, which does not appear to be as heavy as at sites farther upstream. In section 23 (Fig. 10 bottom), located near the exit of a large-radius bend, there is open water on the left side of the ice run but moving ice rubble appears to extend all the way to the shear line separating it from grounded rubble on the right bank. Surface ice concentration is perceptibly heavier than at
Section 17. At Section 22 (Fig. 10 middle), located in the sharp bend at the mouth of Arctic Red River, there is no open water at either side of the ice run, while extensive areas of grounded ice are evident near the banks. Surface ice concentration appears to be the heaviest in this area.

\section{Flow computations}

As already described, the pair of images, taken $45 \mathrm{~s}$ apart, can be processed to calculate and plot the speed distribution for the entire study reach, as illustrated in Figs. 9 and 10. From this information, the ice velocity distribution across each one of the 15 XSs can be obtained and further processed to determine normal $\left(\mathrm{u}_{\mathrm{ice}}\right)$ and transverse $\left(\mathrm{w}_{\text {ice }}\right)$ components, relative to the orientation of the cross-sectional plane. Though every effort is made during the field surveys to align each XS perpendicular to the local flow direction, small discrepancies are inevitable. This largely accounts for non-zero or nonnegligible values of $\mathrm{w}_{\text {ice }}$ that were occasionally encountered and implies that the calculated values of $\mathrm{u}_{\text {ice }}$ are not exactly aligned with the flow direction. This discrepancy does not influence the discharge calculation, which by definition involves the integral of $\mathrm{u}_{\mathrm{N}}$ over the area $\mathrm{A}$ of any one $\mathrm{XS}$, with $\mathrm{u}_{\mathrm{N}}$ being the velocity component normal to the cross-sectional plane. In the present application, $\mathrm{u}_{\mathrm{N}}$ is equal to $\mathrm{u}_{\text {ice }}$ near the surface and is assumed to be parallel to, though smaller than, $u_{i c e}$ farther down in the vertical under consideration.

Typical transverse distributions of $\mathrm{u}_{\text {ice }}$ are shown in Figs. 11-13, along with the corresponding bathymetries for XSs 17, 23, and 22. The very low values at both ends of any one XS are not considered significant and set to zero for the computations. The gaps in the velocity series reflect areas where it was not possible to obtain velocity values from the images, usually as a result of open water between the edge of the ice run and the river bank, or strong changes of the ice pattern over $45 \mathrm{~s}$ that prevented tracking it 
through automatic image correlation. Where the cause of the gap is open water, velocities have been estimated by linear interpolation; they have been set to zero, however, in cases where the images indicate high concentrations of grounded stationary ice.

According to Fig. 10 (top panels), the ice run at XS 17 is relatively loose, being unconfined at both sides and of relatively moderate surface concentration. This suggests that the flow velocity distribution is not significantly affected by the ice, beyond the area occupied by ice that would otherwise been flowing water (see also Supplementary data). It can be noted in Fig. 10 that the ice velocity distribution is consistent with the distribution of the flow depth. This type of linkage is expected in prismatic-channel flows, for which it can be shown that velocity should vary roughly as the two-thirds power of depth (via local application of the Manning equation after neglecting small shear stresses between adjacent vertical parcels of water). In rivers, the depth-velocity linkage may be altered by the channel morphology and the irregular bathymetry that is characteristic of natural streams. A relationship between velocity and depth is more likely to exist in straight sections with small longitudinal variability in bathymetry. These conditions appear to be fulfilled in the case of XS 17 (located at km 1.76 in Fig. 4).

The velocity distribution at XS 22 (Fig. 13) is decidedly different from that of a prismatic channel. Here, the ice is moving faster near the inner bank than over the deep channel closer to the left bank. Figure 10 (middle) indicates that there is a high degree of confinement of the ice run within the tight bend where XS 22 is located and suggests that the ice is having a significant effect in the flow distribution, probably leading to the kind of profile depicted in Fig. 2b (see also Supplementary data).

Ignoring, for the time being, such limitations, the calculation of discharge proceeds according to Eq. 7, which is based on the velocity profile of Fig. 2a. After setting insignificant $u_{\text {ice }}$ values to zero, and interpolating as needed, the submerged aggregate thickness $\left(t_{s}\right)$ of the ice run and its porosity are estimated, based on visual inspection of enlarged images (e.g. Fig. 8). A value of $2 \mathrm{~m}$ was selected for $t_{\mathrm{s}}$ in all but three XSs. This was considered plausible, given that the ice run was already on the falling limb of the jave. By this time, there would have been considerable dispersion and thinning relative to an initial (ice jam) thickness of a few to several metres (Beltaos and Carter, 2009; Beltaos et al., 2012). The three exceptions are XSs 3, 21 and 22 , in which the ice run appears to be highly confined and most likely thicker than elsewhere. Consequently, a value of $3 \mathrm{~m}$ was selected for $\mathrm{t}_{\mathrm{s}}$ at these sites; it is expected that the confinement would also result in lower porosities, which were estimated as 0.45 , not much higher than the commonly used value of 0.40 for breakup ice jams. By contrast, the porosity estimates at other sites were in the range 0.55 to 0.65 . Though all such estimates are uncertain, their influence on the calculated total discharge is small, owing to the relatively small magnitude of the second term on the right-hand side of Eq. 7.

In sections where there was extensive shore-fast ice cover, it was assumed that there was some flow under the ice. The under-ice velocity was estimated by interpolating to the velocity at the edge of the moving ice layer and applying a (subjective) reduction factor of 0.5 to account for unknown but significant effects of the extra hydraulic resistance of the shorefast ice. This is a very small part of the total flow, and any errors in the factor 0.5 would have little percent impact in the calculated value of discharge.

With this information at hand, each $\mathrm{XS}$ is divided into 25 metre-wide segments where the velocity and depth are assumed to be equal to the respective averages of the values determined 
at the end points of each segment. Multiplying average velocity with average depth and segment width $(25 \mathrm{~m})$ and adding over the entire width gives the discharge for that segment. The results of the discharge computations are summarized in Table 1 and shown graphically in Fig. 14.

In general, the computed values appear to be highest $\left(\sim 25000 \mathrm{~m}^{3} / \mathrm{s}\right)$ in the first $20 \mathrm{~km}$ from Point Separation and to decrease farther upstream, to $\sim 20000 \mathrm{~m}^{3} / \mathrm{s}$ towards the end of the study reach. Inspection of Table 1 as well of enlarged images of the ice run (e.g. Fig 10) suggests that the assumptions embodied in Fig. $2 \mathrm{a}$ are most likely to be fulfilled in the first 4 sections where the channel is relatively straight and the ice run minimally confined between the river banks. The constraining influence of the Arctic Red River bend appears to be felt at the remaining sections, especially those located within, and upstream of, the bend.

Based on these observations, the best discharge estimate is the average of sections 17-20, i.e. $\mathrm{Q}_{\text {best }}=24950 \mathrm{~m}^{3} / \mathrm{s}$ (standard deviation $\mathrm{SD}=$ $1640 \mathrm{~m}^{3} / \mathrm{s}$ ). This can be compared to the overall 15 -section average $\left(\mathrm{Q}_{15 \mathrm{avg}}\right)$ of $22760 \mathrm{~m}^{3} / \mathrm{s}(\mathrm{SD}=$ $2026 \mathrm{~m}^{3} / \mathrm{s}$ ), which is about $9 \%$ lower than the 4section value. It follows that even an uncritical application of Eq. 7 would still indicate a value not far from the "best estimate". The lowest single-section estimate is $\sim 20000 \mathrm{~m}^{3} / \mathrm{s}$, some $20 \%$ less than $Q_{\text {best; }}$ on the average, discharge estimates for the 11 "bend-influenced" sections are $12 \%$ lower than $Q_{\text {best }}$. Within the 4-section set of best estimates, the discrepancy from $\mathrm{Q}_{\text {best }}$ is at most $8 \%$ and this figure could be considered representative of the uncertainty associated with data acquisition and processing errors, not only as concerns the imagery and displacement matching, but also the bathymetry of the river and the estimated slope of the water surface. This kind of uncertainty is somewhat more than, but in the same ballpark as, the error associated with actual measurements of discharge in open-water flow and in flow under a stationary sheet ice cover without slush deposits (5-6\%; Pelletier 1988; Bourdages, pers. comm. 2009).

As noted earlier, the flow at the upstream end of the study reach should be less than the flow at the downstream end by some $230 \mathrm{~m}^{3 /} \mathrm{s}$ as a result of the decreasing stage when the images were taken. To this, one should add $294 \mathrm{~m}^{3 /} \mathrm{s}$ to account for the flow of Arctic Red River. This value is based on WSC estimates for the gauge 10LA002, "Arctic Red River near the mouth". The total of $\sim 530 \mathrm{~m}^{3 /} \mathrm{s}$ represents $2 \%$ of $\mathrm{Q}_{\mathrm{bset}}$, reducing slightly the discrepancy between the downstream sections and the upstream ones.

The published WSC daily mean value at MARR of $23800 \mathrm{~m}^{3} / \mathrm{s}$ is enhanced to $24090 \mathrm{~m}^{3} / \mathrm{s}$ by the flow of the Arctic Red River, a value that is reasonably close to Qbest. Though WSC estimates at MARR are known to be subject to considerable uncertainty (Beltaos, 2012) the consistency among all of the aforementioned figures, provides strong support for the use of satellite imagery as a tool for estimating breakup flows.

As a check on the effects of the assumed thickness of the ice run, an alternative computation was carried out using a general $t_{s}$ value of $3 \mathrm{~m}$ (instead of $2 \mathrm{~m}$ ) and $4 \mathrm{~m}$ at the MARR bend (instead of $3 \mathrm{~m}$ ). This operation indicated that the slope of the water surface would have to be changed to $0.032 \mathrm{~m} / \mathrm{km}$ (so as to maintain $\mathrm{n}$ at 0.025 ) while the resulting discharges were reduced by $\sim 2 \%$. 
potentially limiting factor because smaller steams tend to be steeper than larger ones.

- One or more ground points of known UTM coordinates, which are identifiable in the satellite images, can be used to fine-tune the georeference coordinates associated with the imagery. Otherwise one has to rely on the georeference information provided with the satellite data, which may have errors of metres to tens of metres.

This study was possible only because of the fortuitous availability of archived satellite records, which currently contain limited and short intervals of relevant data for river freezeup and breakup periods. For future applications, acquisition plans of existing and upcoming airborne and spaceborne missions could be modified to target selected rivers around freezeup and breakup periods, thereby greatly enhancing the applicability of the method (Kääb and Prowse, 2011; Kääb et al. 2013). As for all optical space-based methods, however, the method presented here is restricted for use with cloud-free day-time data, a particular limitation for high latitudes at freezeup. The typical repeat times of a few weeks of medium to high resolution optical Earth observation satellites, including stereo satellites such as ALOS PRISM used here, ASTER or SPOT5, in the same nominal orbit bear in addition the risk to completely miss suitable river ice conditions. Steerable satellites or constellations of satellites such as Ikonos, WorldView or Pleiades however, allow for stereo acquisitions with repeat times of a few days by being able to observe targets from different orbits through cross-track pointing maneuvers. Such operations are, however, expensive and may cost several thousand USD per acquisition (as of 2013). In contrast, data from ALOS PRISM, or ASTER, for example are cheaper (USD 80-500, commercial rates), or often even free for research applications. Data of above satellites (Ikonos, WorldView, or Pleiades, for instance) can be available to the user within a few hours

- Water surface elevations along the study reach, typically obtainable via a nearby gauge and estimated slope of the water surface. It would be worth keeping in mind that errors associated with this approach increase with increasing slope, which may point to stream size as a 
or days, and the processing exemplified here can be accomplished within a few hours. The approach is thus for now not suited for real-time applications, but rather for occasional spatial comparison to terrestrial point or profile measurements, and for investigating spatial processes of river flow and river ice. In principle, all information to measure ice/water velocity fields from satellite stereo data is contained in the satellite data themselves. Availability of one or few ground control points improves the absolute georeference accuracy and thus comparison to other data. The accuracy of measured velocities is however not affected by the lack of such points.

A new category of satellite data suitable for tracking river ice could come in the near future from constellations of small satellites carrying video or high-frequency imaging sensors such as planned by the companies 'Skybox Imaging' and 'Planet Labs'.

The minimum river width where ice debris displacements can be measured is mainly governed by the spatial resolution of the instrument used. In our study, the $2.5 \mathrm{~m}$ image resolution and $50 \mathrm{~m}$-wide correlation templates suggest a minimum river width on the order of a few hundred metres for PRISM data. For typical $0.5 \mathrm{~m}$ to $1 \mathrm{~m}$ resolution data from, for instance, Ikonos, Quickbird or WorldView, the minimum river width could be on the order of $100 \mathrm{~m}$ or less. These minimum width figures suggest that discharge estimation via satellite imagery is feasible for many cold regions rivers, rendering the present methodology a valuable tool in the study of ice breakup processes and their various impacts. More accurate estimates of northern flows would also be invaluable to improving our understanding of the freshwater budget of the Arctic Ocean, which is known to have important implications for global climate. Although the demonstrated approach relies on ice debris as surface markers, and this means that it is restricted to cold region rivers and over specific periods (freezeup and breakup), other potential tracers, such as drifting matter, sediment plumes or infrared and thermal variations, could expand its application to other regions (Kääb and Prowse, 2011).

\section{Summary and conclusions}

The present results have demonstrated for the first time that credible estimates of river discharge during the breakup of the ice cover can be obtained from time-lagged pairs of satellite images depicting moving ice on the river surface. The hydraulic principle invoked in the computation of discharge is the stable ratio of average-to-surface velocity in any one vertical. Best results are obtained where this principle is likely to apply with minimal error, i.e. in straight river segments, where the flow is not affected by the proximity of tight bends upstream or downstream, and where the ice run is not very dense or strongly confined between the banks. Errors associated with tight bends and dense ice runs result in lower discharge values, but are not extreme $(\sim 12 \%$ on the average and up to $\sim 20 \%$ for this study) and could be acceptable, depending on the type of intended usage and given the uncertainties associated with gauge-derived estimates during breakup.

Ice velocities were tracked with an accuracy on the order of the resolution of the satellite images employed, here $\sim \pm 3 \mathrm{~m}$ or $\sim \pm 0.07 \mathrm{~m} / \mathrm{s}$. As this accuracy applies for individual displacement measurements, higher accuracy is expected where individual velocities are spatially averaged in the analysis, leading to reduction of the random noise (Kääb et al., 2013).

So far, satellite data archives contain only occasionally suitable data at suitable times over a river reach of interest. However, systematically targeting rivers during freezeup and ice breakup using satellite stereo missions (Kääb et al., 2013) or airborne stereo flights has the potential to advance the understanding of processes related to river flow and river ice for scientific and applied purposes such as hydrology, ecology, hydraulics, engineering or natural hazard management. 


\section{Acknowledgments}

The hydraulic and bathymetric data used in this article derive from previous studies that were financially supported by the Canadian component of IPY, by the Mackenzie Delta Oil and Gas Environmental Assessment Project, and by Environment Canada. Field surveys for these studies were conducted by Tom Carter, Charlie Talbot, Cory Treen, and Earl Walker (ret.) of Environment Canada with the assistance of Delta navigator and bear monitor Willy Simon of Inuvik, whose participation in the summer field teams was a key component of successful and safe completion of the work. Randy Wedel and Angus Pippy of the WSC Yellowknife office kindly provided archived hydrometric and observational information. The ALOS PRISM data are courtesy of the European Space Agency under AOALO.3579. For the research leading to these results A.K. has received funding from the European Research Council under the European Union's Seventh Framework Programme (FP/2007-2013) / ERC Grant Agreement $n$. 320816. The work is also a pre-study for the ZEarth stereo mission proposal (http://www.legos.obsmip.fr/recherches/missions-satellites/z-earth).

\section{References}

Beltaos, S. 2007. River ice breakup processes: Recent advances and future directions. Can. J. of Civ. Eng., 34(6), 703-716.

Beltaos, S. 2008a. Chapter 6: Onset of breakup. In: River Ice Breakup, Water Resources Publications, Highlands Ranch, Co., USA. Pp. 167-206.

Beltaos, S. 2008b. Chapter 7. Ice jams. In: River Ice Breakup, Water Resources Publications, Highlands Ranch, Co., USA. Pp. 207-246.

Beltaos, S. 2011. Developing winter flow rating relationships using slope-area hydraulics. River Research and Applications. 27(9): 1076-1089.

Beltaos, S. 2012. Mackenzie Delta flow during spring breakup: Uncertainties and potential improvements. Canadian Journal of Civil Engineering. 39(5): 579588.
Beltaos, S. 2013. Hydrodynamic characteristics and effects of river waves caused by ice jam releases. Cold Regions Science and Technology 85: 42-55

Beltaos, S. and Carter, T. 2009. Field studies of ice breakup and jamming in the Mackenzie Delta. Proceedings, 15th Workshop on River Ice (F. Hicks and S. Warren, co-chairs), St. John's, NL, June 15 17, 2009, CGU HS Committee on River Ice Processes and the Environment, Edmonton, 266-283.

Beltaos, S., Carter, T., and Rowsell, R. 2012. Measurements and analysis of ice breakup and jamming characteristics in the Mackenzie Delta, Canada. Cold Regions Science and Technology, 82: 110-123.

Beltaos, S., Prowse, T.D. and Carter, T. 2006. Ice regime of the lower Peace River and ice-jam flooding of the Peace-Athabasca Delta. Hydrological Processes, Volume 20, Issue 19, pp 4009-4029.

de Michele, M., Leprince, S., Thiebot, J., Raucoules, D. and Binet, R. 2012. Direct measurement of ocean waves velocity field from a single SPOT-5 dataset. Remote Sensing of Environment. 119, 266-271.

Garay, M.J. and Diner, D.J. 2007. Multi-angle Imaging SpectroRadiometer (MISR) time-lapse imagery of tsunami waves from the 26 December 2004 SumatraAndaman earthquake. Remote Sensing of Environment. 107(1-2), 256-263.

Goldstein, R.M. and Zebker, H.A. 1987. Interferometric radar measurement of ocean surface currents. Nature. 328(6132), 707-709.

Graber, H.C, D.R. Thompson, R.E. Carande 1996, Ocean surface features and currents measured with synthetic aperture radar interferometry and HF radar, J. Geophys. Res. , 101, C11, 25813-25832.

Emmerton, C.A., Lesack, L.F.W. and Vincent, W.F. 2008. Mackenzie River nutrient delivery to the Arctic Ocean and effects of the Mackenzie Delta during open water Conditions. Global Biogeochemical Cycles, 22, GB1024, 15 p, Doi:10.1029/2006gb002856.

Heid, T. and Kääb, A. 2012. Evaluation of existing image matching methods for deriving glacier surface displacements globally from optical satellite imagery. Remote Sensing and Environment. 118, 339-355.

Jasek, M. and Beltaos, S. 2008. Chapter 8. Ice-jam release: javes, ice runs and breaking fronts. In: River Ice Breakup, Water Resources Publications, Highlands Ranch, Co., USA. Pp. 247=303. 
Jasek, M., Muste, M., and Ettema, R. 2001. Estimation of Yukon River discharge during an ice jam near Dawson City. Can. J. Civ. Eng. 28: 856-864.

Jodeau, M., Hauet, B., Paquiera, A., Le Coza, J., and Dramais, G. 2008. Application and evaluation of LSPIV technique for the monitoring of river surface velocities in high flow conditions. Flow Measurement and Instrumentation 19: 117-127.

Kääb, A. 2013. Image correlation software CIAS. http://mn.uio.no/icemass (last visited 9 Aug 2013).

Kääb, A. and Vollmer, M. 2000. Surface geometry, thickness changes and flow fields on creeping mountain permafrost: automatic extraction by digital image analysis. Permafrost and Periglacial Processes. 11(4), 315-326.

Kääb, A. and Prowse, T. 2011. Cold-regions river flow observed from space. Geophysical Research Letters. 38(8), L08403.

Kääb, A., Lamare, M., and Abrams, M. 2013. River ice flux and water velocities along a $600-\mathrm{km}$ long reach of Lena River, Siberia, from satellite stereo. Hydrology and Earth System Sciences Discussions. 10: 9967-9997.

Kim, Y., Muste, M., Hauet, A., Krajewski, W. F., Kruger, A., and Bradley, A. 2008. Stream discharge using mobile large-scale particle image velocimetry: A proof of concept. Water Resources Research, 44, W09502, 6 p.

Lavergne, T., S. Eastwood, Z. Teffah, H. Schyberg, and L.-A. Breivik 2010. Sea ice motion from lowresolution satellite sensors: An alternative method and its validation in the Arctic, J. Geophys. Res. , 115, C10032.

Marsh, P., Lesack, L. and Roberts, A. 1993. The environmental effects of ice jam flooding on lakes in the Mackenzie Delta. Proc., Workshop on Environmental Aspects of River Ice, Saskatoon, Canada (NHRI Symposium no. 12, ed. by T.D. Prowse), 359381

Matthews, J. 2005. Stereo observation of lakes and coastal zones using ASTER imagery. Remote Sensing of Environment. 99(1-2), 16-30.

Matthews, J.P. and Awaji, T. 2010. Synoptic mapping of internal-wave motions and surface currents near the Lombok Strait using the Along-Track Stereo Sun Glitter technique. Remote Sensing of Environment. 114(8), 1765-1776.

Matthews, D. K., and W. J. Emery 2009. Velocity observations of the California Current derived from satellite imagery, J. Geophys. Res., 114, C08001

Melcher, N.B. and Walker, J.F. 1992. Evaluation of selected methods for determining streamflow during periods of ice effect. US Geological Survey Water Supply paper 2378, Denver, CO, U.S.A., 47 p.
Mermoz, S., Allain, S., Bernier, M., Pottier, E. and Gherboudj, I. 2009. Classification of river ice using polarimetric SAR data. Canadian Journal of Remote Sensing. 35(5), 460-473.

Muste, M., Fujita, I., and Hauet, A. 2008. Large-scale particle image velocimetry for measurements in riverine environments. Water Resources Research, 44, W00D19, 14p.

Pavelsky, T.M. and Smith, L.C. 2009. Remote sensing of suspended sediment concentration, flow velocity, and lake recharge in the Peace-Athabasca Delta, Canada. Water Resources Research. 45, -.

Pelletier, P. M. 1988. Uncertainties in the Single Determination of River Discharge: A literature review, Canadian Journal of Civil Engineering, Vol. 15, No. 5, pp. 834-850.

Polatel, C. 2005. Indexing free-surface velocity: A prospect for remote discharge estimation, paper presented at 31st Congress, Int. Assoc. of Hydraul. Eng. and Res., Seoul, South Korea.

Prowse TD, Culp JM. 2003. Ice breakup: a neglected factor in river ecology. In: River Ice Breakup, Water Resources Publications, Highlands Ranch, Co., USA. Pp 349-375.

Romeiser, R., H. Runge, S. Suchandt, J. Sprenger, H. Weilbeer, A. Sohrmann, and D. Stammer. 2007. Current measurements in rivers by spaceborne alongtrack InSAR, IEEE Trans. Geosci. Rem. Sens., 45(12), 4019-4031.

Romeiser, R., S. Suchandt, H. Runge, U. Steinbrecher and S. Gr ünler. 2010. First analysis of TerraSAR-X along-track InSAR-derived current fields, IEEE Trans. Geosci. Rem. Sens., 48(2), 820-829.

Rosenberg, H.B. and Pentland, R.L. 1983. Accuracy of winter streamflow records, Inland Waters Directorate, Direction générale des eaux intérieures, Ottawa, Canada (reprinted from the Proceedings of the 43rd Eastern Snow Conference, 1966, Hartford, U.S.A., 5172).

Shiklomanov, A.I., Yakovleva T.I., Lammers R.B., Karasev I.P., Vőrősmarty, C.J., and Linder, E. 2006. Cold region river discharge uncertainty - estimates from large Russian rivers. Journal of Hydrology 326: 231-256.

Siegmund, R., Bao, M.Q., Lehner, S. and Mayerle, R. 2004. First demonstration of surface currents imaged by hybrid along- and cross-track interferometric SAR. IEEE Transactions on Geoscience and Remote Sensing. 42(3), 511-519.

Smith, L.C. 2002. Emerging applications of interferometric synthetic aperture radar (InSAR) in geomorphology and hydrology. Annals of the Association of American Geographers. 92(3), 385398. 
Unterschultz, K.D., van der Sanden, J. and Hicks, F.E. 2009. Potential of RADARSAT-1 for the monitoring of river ice: Results of a case study on the Athabasca River at Fort McMurray, Canada. Cold Regions Science and Technology. 55(2), 238-248.

Vincent, F., Raucoules, D., Degroeve, T., Edwards, G. and Mostafavi, M.A. 2004. Detection of river/sea ice deformation using satellite interferometry: limits and potential. International Journal of Remote Sensing. 25(18), 3555-3571.

White, K.D. and Beltaos, S. 2008. Chapter 9. Development of ice-affected stage frequency curves. In: River Ice Breakup, Water Resources Publications, Highlands Ranch, Co., USA. Pp. 327-348.

Yalin, M.S. 1977. Mechanics of sediment transport. Pergamon Press, Toronto.

Table 1. Summary of flow computations, all cross-sections

\begin{tabular}{|r|r|r|l|}
\hline \multicolumn{1}{|l|}{$\begin{array}{l}\text { XS } \\
\text { Number }\end{array}$} & $\begin{array}{l}\text { Location } \\
(\mathrm{km})\end{array}$ & $\begin{array}{l}\text { Discharge } \\
\left(\mathrm{m}^{3} / \mathrm{s}\right)\end{array}$ & Site description and lateral extent of ice run \\
\hline 17 & 1.76 & 25716 & straight channel, ow ${ }^{2}$ on both sides of ice run \\
\hline 18 & 6.60 & 23949 & straight, ow on left side of ice run \\
\hline 19 & 11.09 & 23271 & straight, ow on left side of ice run \\
\hline 20 & 15.78 & 26864 & straight, ow both sides of ice run \\
\hline 5 & 20.68 & 23715 & bend, ow on left side of ice run \\
\hline 4 & 22.87 & 24039 & mild bend ow on right side of ice run \\
\hline 21 & 24.06 & 23569 & sharp bend, ice bank to bank \\
\hline 3 & 24.78 & 20214 & sharp bend, ice bank to bank \\
\hline 22 & 24.85 & 21003 & sharp bend, ice bank to bank \\
\hline 2 & 27.28 & 21647 & very mild bend, ice bank to bank \\
\hline 1 & 29.22 & 22510 & almost straight, ice bank to bank \\
\hline 23 & 32.89 & 21227 & bend, ow on left side of ice run \\
\hline 24 & 35.85 & 19724 & bend, ice bank to bank \\
\hline 25 & 38.75 & 20675 & bend, minor strip of ow on left side of ice run \\
\hline 26 & 41.76 & 23244 & bend, ow both sides but ice bank to bank just ds ${ }^{3}$ \\
\hline
\end{tabular}

(1) River distance upstream of Point Separation; (2) ow = open water; (3) ds = downstream 


\section{Figures}

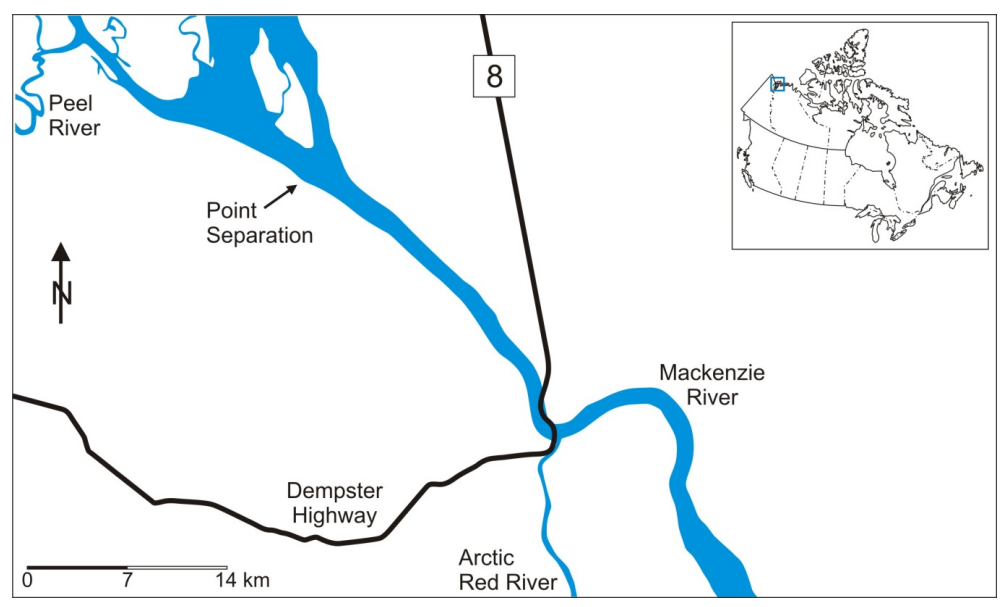

Figure 1. Plan view of study area. The MARR gauge is located across from the mouth of Arctic Red River
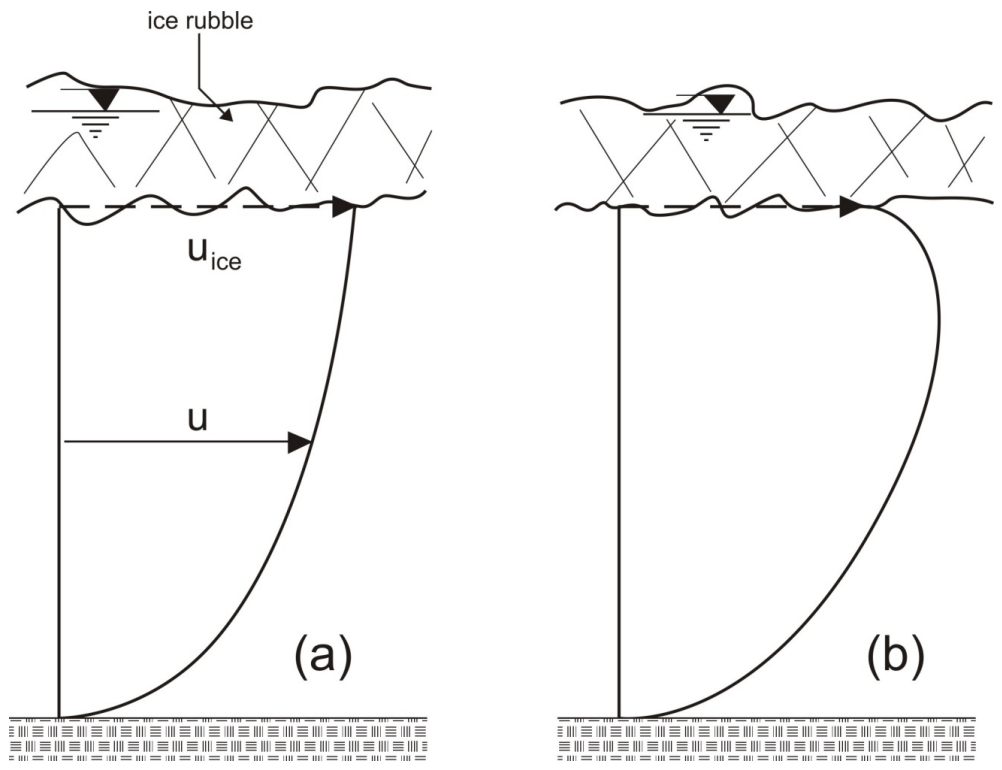

Figure 2. Velocity distribution under a moving layer of ice rubble. Case (a): unconstrained ice motion - logarithmic distribution. Case (b): constrained ice motion - maximum velocity occurs some distance below bottom of ice layer. 


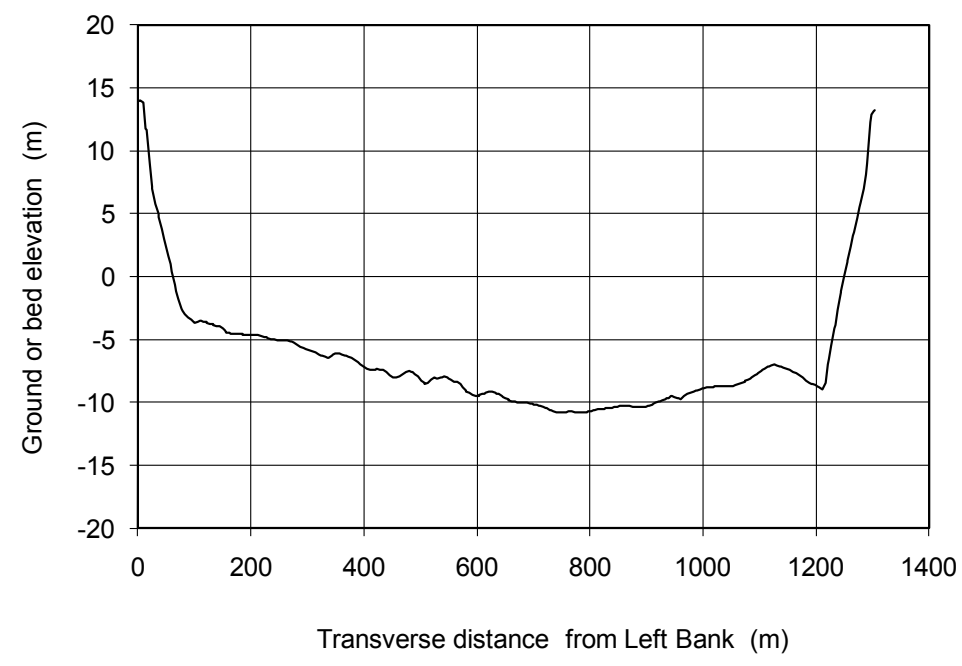

Figure 3. Channel cross section located $6.6 \mathrm{~km}$ upstream of Point Separation, surveyed Sept. 16, 2009. "Left/Right" convention applies to a downstream-facing observer.

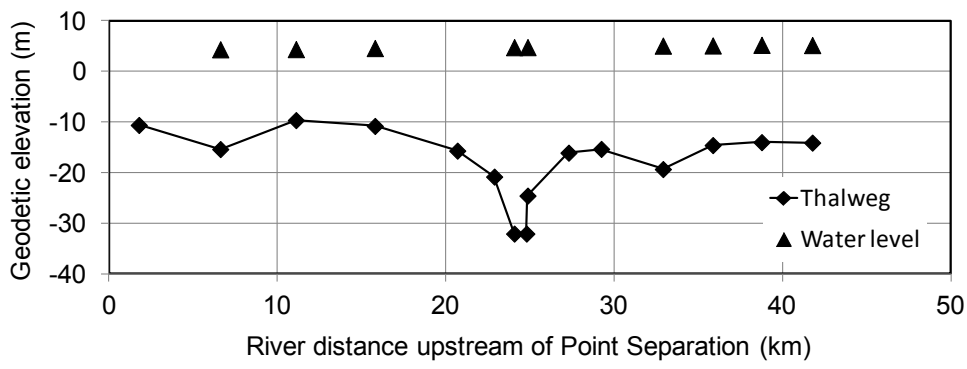

Figure 4. Longitudinal profile of Mackenzie River along the study reach. Water levels are based on local surveys in September of 2009, and adjusted to Sept. 15. 


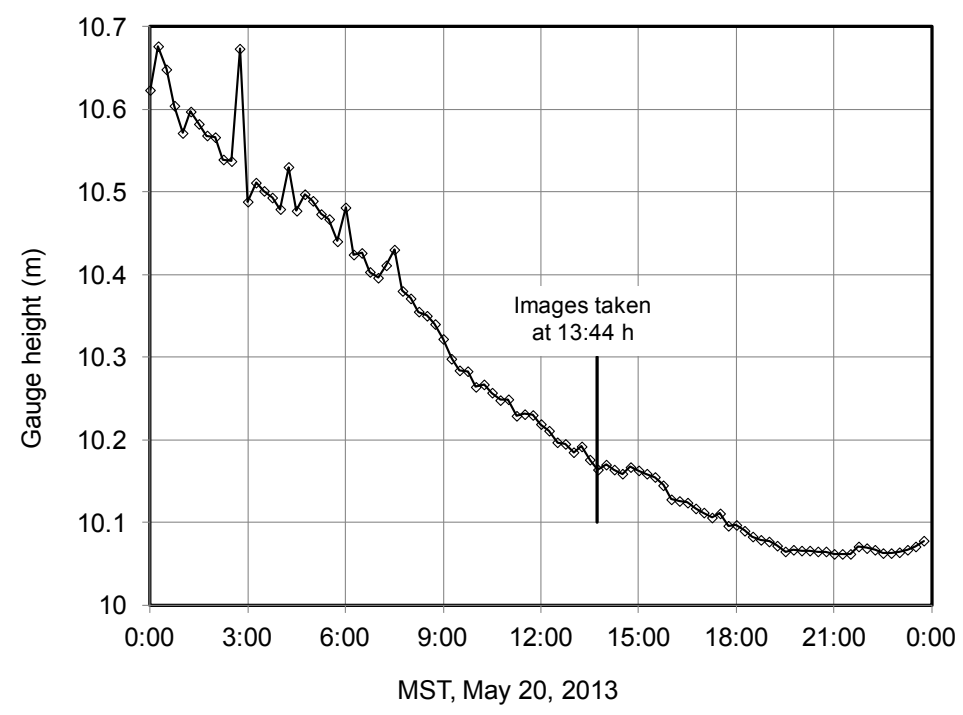

Figure 5. Variation of water level at the MARR gauge site during May 20, 2013, based on 15minute data provided by WSC.

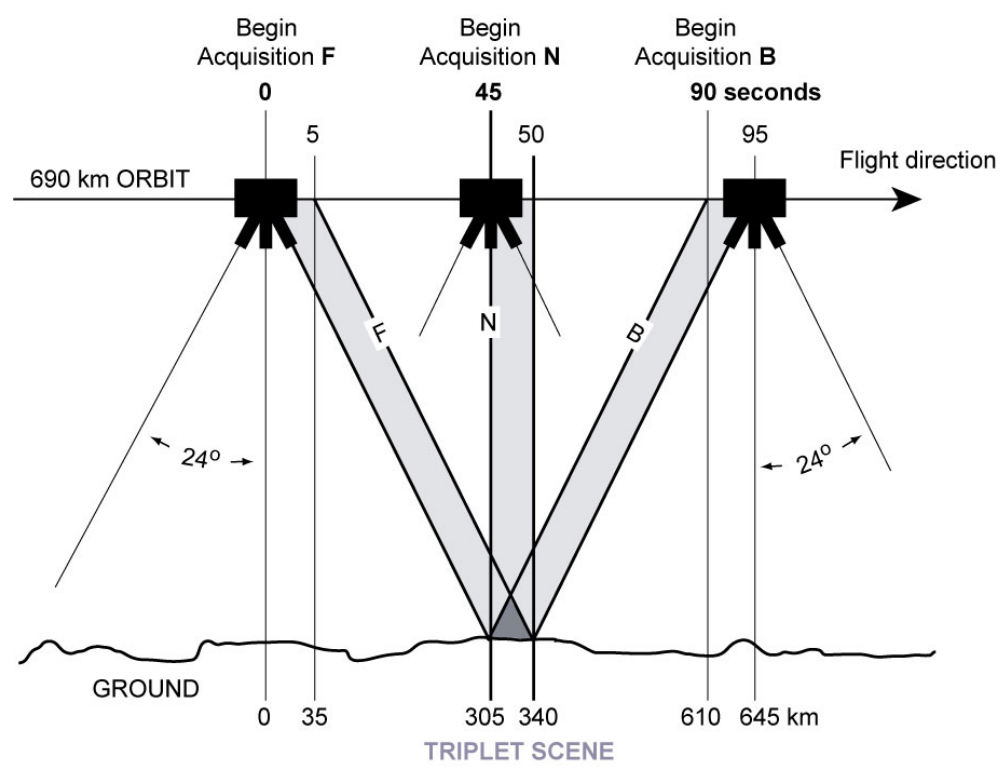

Figure 6. Acquisition geometry of the PRISM instrument onboard the ALOS satellite. The forward image $\mathrm{F}$, the nadir image $\mathrm{N}$ and the backward image $\mathrm{B}$ are taken with time lags of $45 \mathrm{~s}$ or 90 s, respectively. 


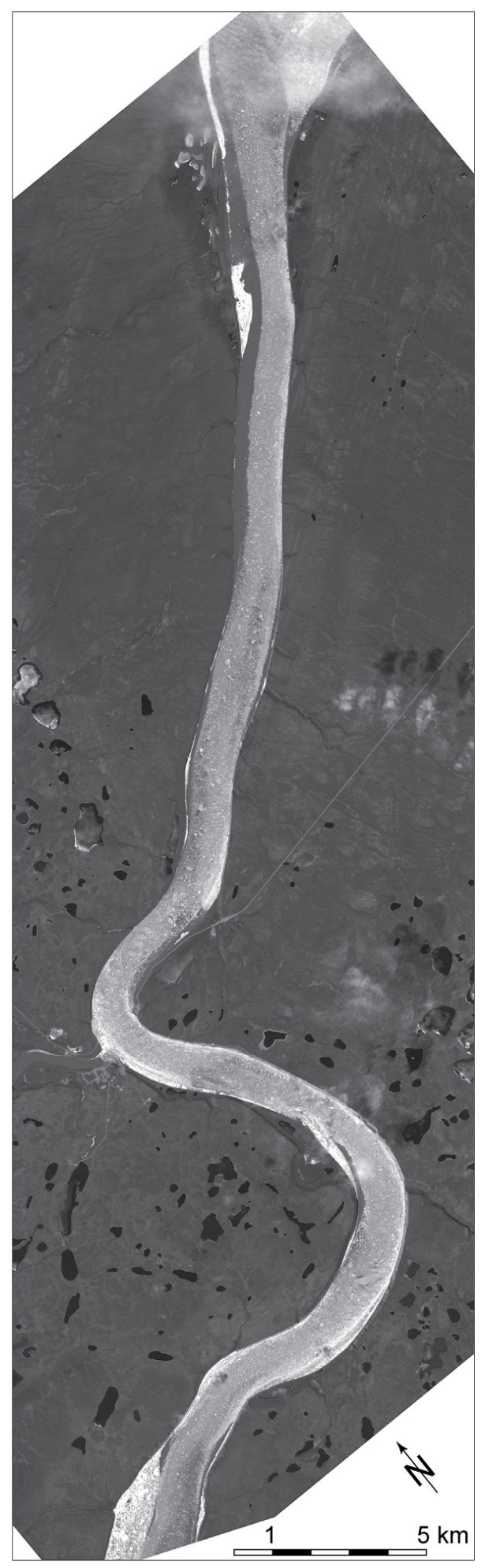

Figure 7. Raw PRISM nadir satellite image of study reach, 13:44 h (MST), May 20, 2010. 

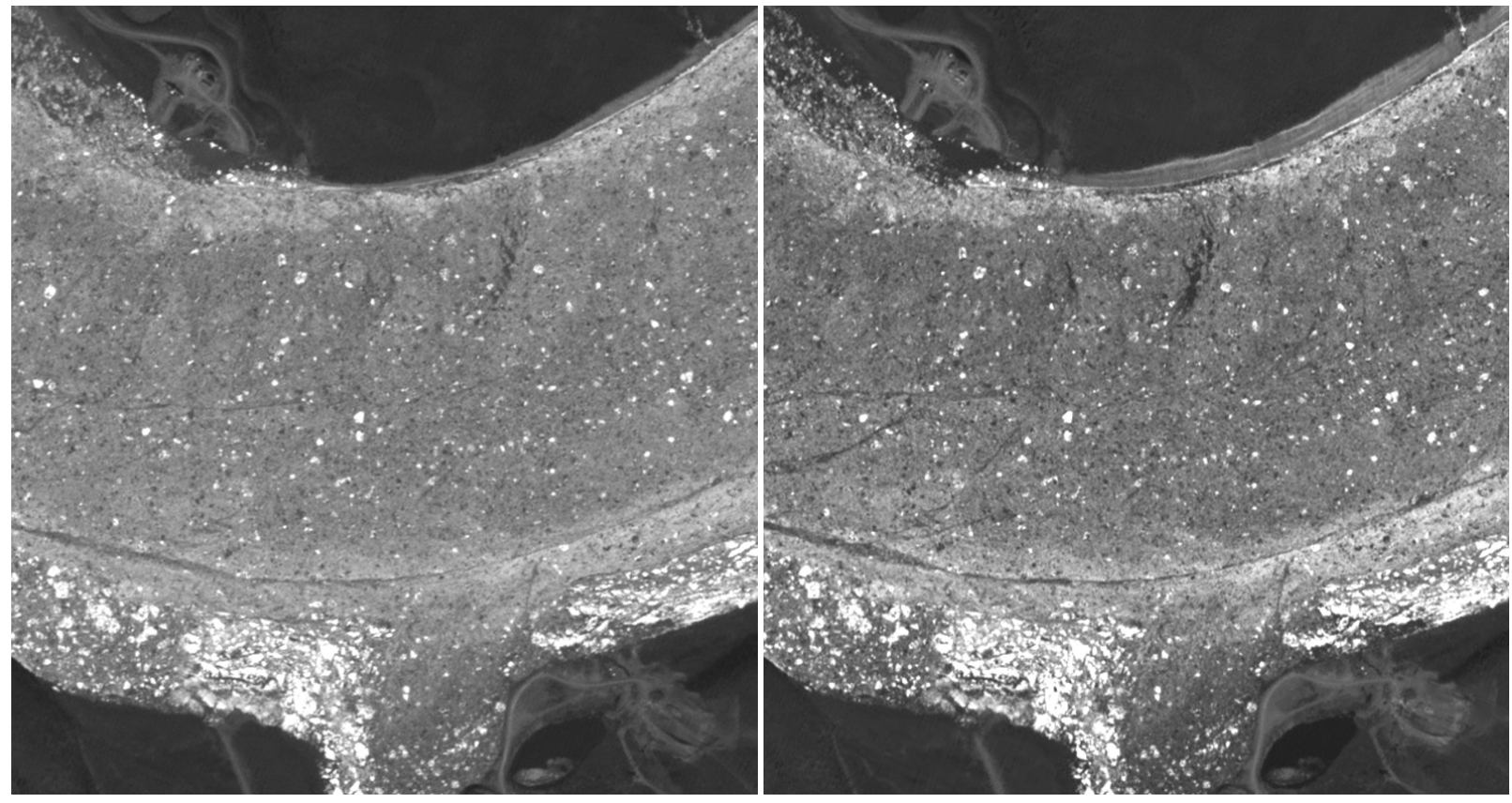

Figure 8. Forward (left) and backward (right) channel images of MARR site illustrating moving ice rubble in main stream and stationary rubble near the banks and at the mouth of Arctic Red River. Images taken 90s apart; North direction is upwards; channel width $\sim 1000 \mathrm{~m}$. (See Supplementary data for animations). 


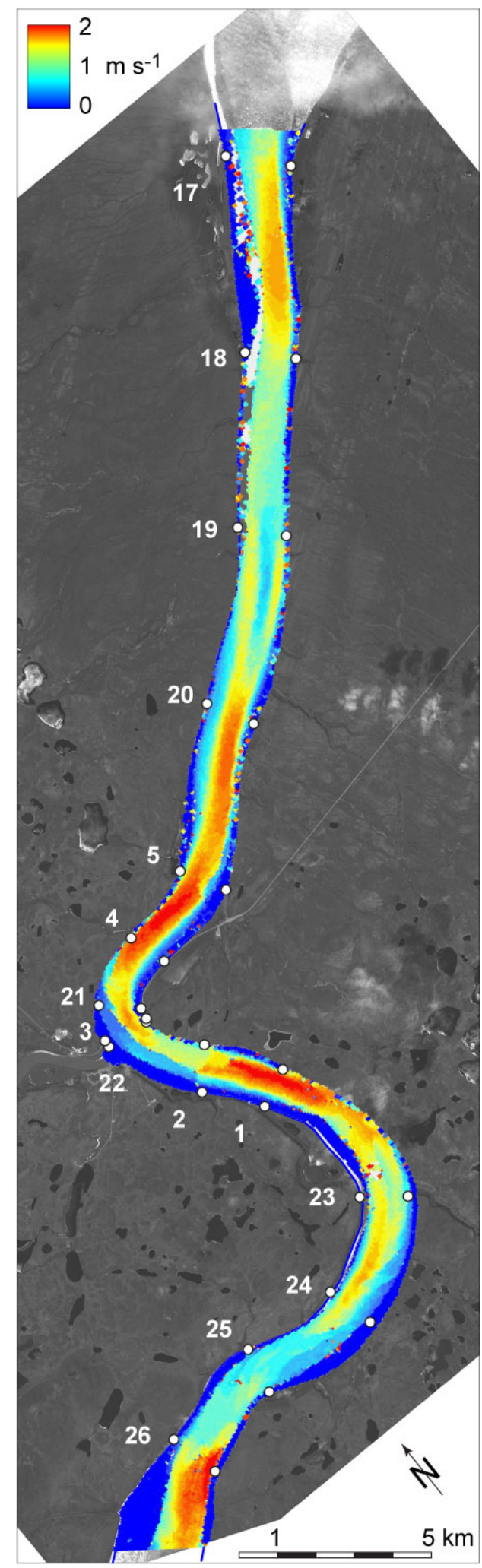

Figure 9. Ice speeds as of 13:44 h (MST), May 20, 2010 over the entire river reach observed, based on the forward-nadir measurements. White numbers and circles indicate cross-sections. "Speed" refers to the magnitude of a velocity vector). 

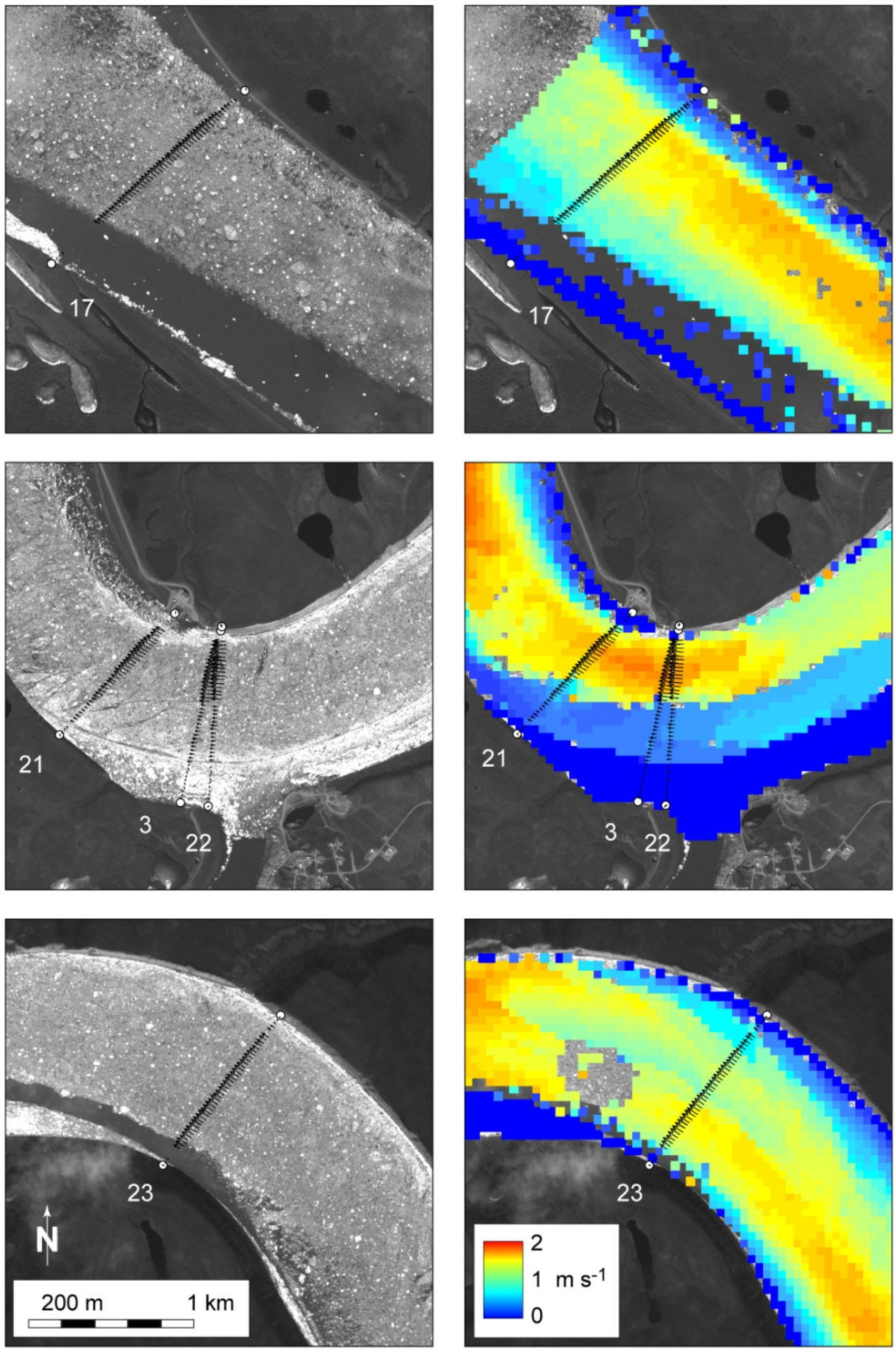

Figure 10. Raw image sections (left column) and ice speeds (right column). White numbers indicate cross-sections (XS). Ice velocities over the cross-sections are indicated as vectors. XS 17 (upper line): relatively unconstrained velocities, XS 22 (middle line): constrained velocities, XS 23 (lower line): moderately constrained velocities. (See Supplementary data for animations). 


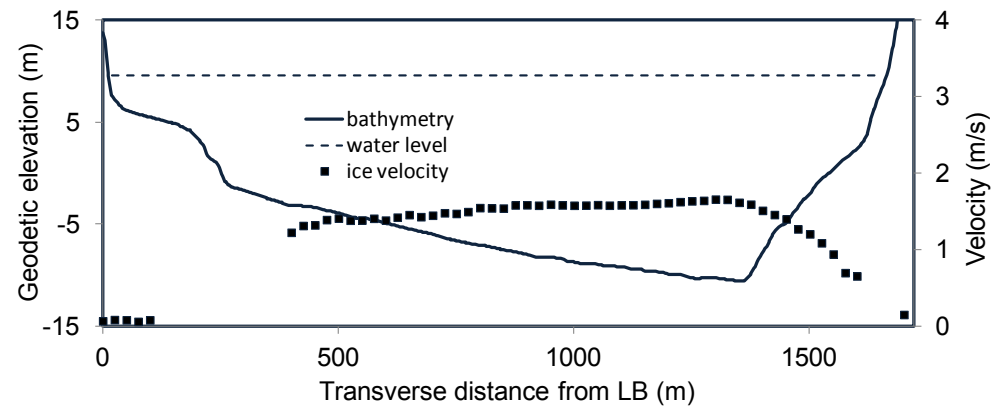

Figure 11. Channel bathymetry and normal component of ice velocity $\left(\mathrm{u}_{\mathrm{ice}}\right)$ at XS 17. "LB" stands for left bank; left-right convention is for a downstream facing observer.

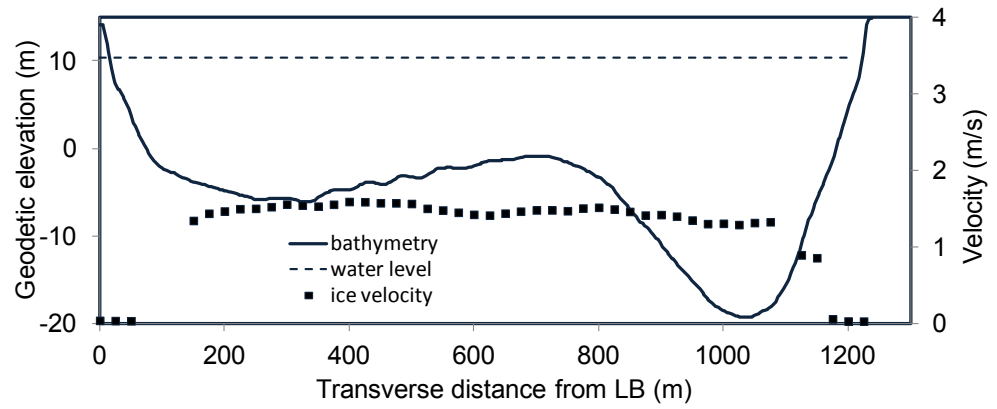

Figure 12. Channel bathymetry and normal component of ice velocity $\left(\mathrm{u}_{\text {ice }}\right)$ at XS 23 .

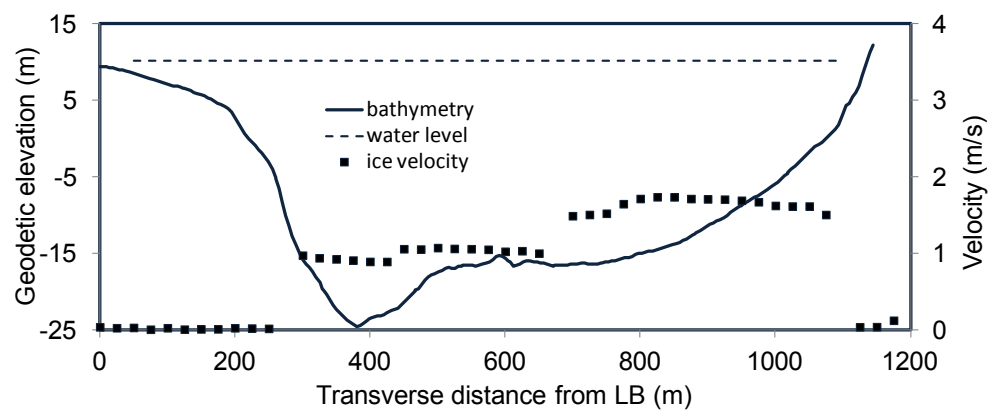

Figure 13. Channel bathymetry and normal component of ice velocity $\left(\mathrm{u}_{\mathrm{ice}}\right)$ at XS 22 . 


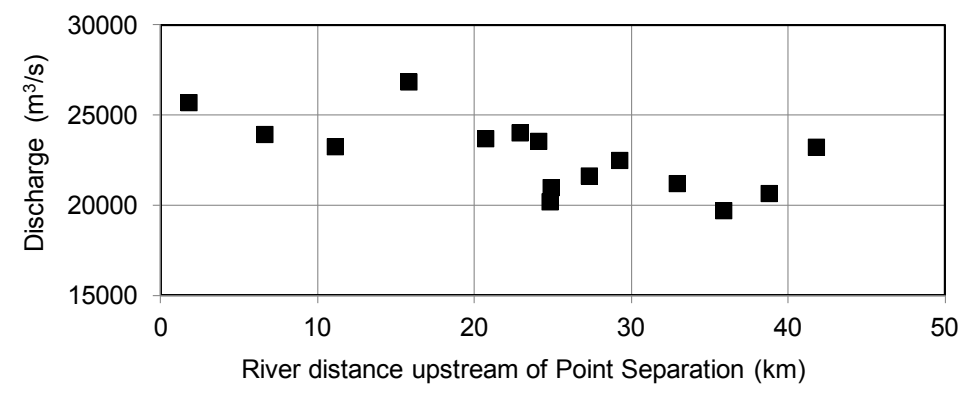

Figure 14. Variation of computed discharge along the study reach. 